\title{
CONSEQUÊNCIAS DA (NÃO) REVELAÇÃO DA HOMOSSEXUALIDADE E PRECONCEITO SEXUAL: O PONTO DE VISTA DAS PESSOAS HOMOSSEXUAIS
}

\author{
Gabrielle Poeschl ${ }^{12}$ \\ Joana Venâncio ${ }^{2}$ \\ Daniel Costa ${ }^{2}$
}

Resumo: O estudo examina a representação dos/as homossexuais na forma como os homens gays são percepcionados pela população em geral e a relação entre esta representação e a percepção das consequências de revelar ou não a homossexualidade. Os resultados indicam que os/as respondentes julgam pouco provável que os homossexuais assumidos experimentem sentimentos negativos e que os homossexuais não assumidos sejam discriminados. Adicionalmente percepcionam como fracos os níveis de preconceito e de motivação das pessoas heterossexuais para responder sem preconceito. Ao contrário do esperado, as consequências da revelação da homossexualidade não estão relacionadas com os níveis de preconceito percepcionados mas com a percepção da motivação para responder de forma não preconceituosa, estando uma maior motivação de fonte interna relacionada com uma menor probabilidade dos homossexuais assumidos serem discriminados.

Palavras-chave: homofobia, preconceito sexual, coming out, percepção social, atribuição causal

Consequences of (non) disclosure of homosexuality and sexual prejudice: The point of view of homosexuals (Abstract): The study examines homosexuals' representation of the way gay men are perceived by the population in general, and the relationship between this representation and the perception of the consequences of disclosing or concealing homosexuality. Results indicate that respondents view as little probable that gay men who disclose their sexual orientation experiment neg ative feelings and that gay men who conceal homosexuality be discriminated. They perceive as low heterosexuals' levels of prejudice and of motivation to respond

\footnotetext{
${ }^{1}$ Endereço para a correspondência: Rua Alfredo Allen, 4200-135 Porto, Portugal (e-mail: gpoeschl@fpce.up.pt).

2 Universidade do Porto
} 
without prejudice. Contrary to our expectative, the consequences of disclosing homosexuality are not related with the perceived levels of homophobia but with the perception of the motivation to respond without prejudice, higher levels of internal motivation being related with the perception of a lower probability that gay men who disclose homosexuality suffer discrimination.

Keywords: homophobia, sexual prejudice, self-disclosure, social perception, causal attribution

\section{Consequências da (não) revelação da homossexualidade e pre- conceito sexual: $O$ ponto de vista das pessoas homossexuais}

Apesar de nos últimos 50 anos a homossexualidade ter sido alvo de uma atenção particular, os registos teóricos permitem verificar que esta sempre existiu. Assim, o presente artigo começa por apresentar algumas variações nas posições acerca da homossexualidade ao longo da história antes de descrever diversas formas sob as quais se traduz, na actualidade, a intolerância contra a minoria homossexual, que tornam difícil para as pessoas homossexuais a decisão de revelar a sua orientação sexual. Apresenta, por último, um estudo empírico realizado junto da minoria homossexual, com o intuito de apreender as suas percepções relativamente às consequências da revelação ou não revelação da homossexualidade, ao nível de preconceito da população heterossexual e às motivações desta população para responder de forma não preconceituosa aos homens homossexuais.

\section{Homossexualidade: variações ao longo da história}

Ao contrário do que se acredita comumente, o comportamento homossexual não foi sempre visto como errado. Em várias civilizações antigas da Ásia, África, Médio Oriente e América do Sul era considerado normal, ou era mesmo encorajado, como na Grécia, onde fazia parte do tecido social, de tradições e ritos de iniciação que ocorriam entre adultos e jovens (Naphy, 2004). O facto é que, a certa altura, a homossexualidade começou a ser tida como algo de errado ou de anormal.

O motivo da mudança poderá ter como base a tradição judaico-cristã e as interpretações das suas Escrituras (Naphy, 2004): por necessidade de assegurar a linhagem, os povos israelitas, constantemente acossados e ameaçados por vários outros, tinham, com efeito, condenado o prazer e definido a homossexualidade como pecado. Assim, a partir da Idade Média, os comportamentos homossexuais foram incluídos na luta contra todas as formas de 
comportamentos não normativos. Observou-se uma tendência para aglomerar práticas como a feitiçaria e a ligação ao demónio, e grupos como os heréticos, judeus e homossexuais, numa só categoria distinta e ameaçadora.

Portanto, o preconceito judaico-cristão do Ocidente desenvolveu-se nos últimos 500 anos, acabando por se alastrar por todo o mundo como resultado da hegemonia europeia do Séc. XIX e do domínio cultural e económico dos EUA nos últimos 100 anos (Naphy, 2004). Parece ter havido uma espécie de colonização das mentes no que diz respeito às relações sexuais, uma vez que as atitudes negativas face à homossexualidade (pecado) e aos homossexuais (pecadores) foram adoptadas e assimiladas pela maioria das culturas não-ocidentais.

Uma outra causa de hostilidade face à homossexualidade foi a sua classificação como patologia pela comunidade médica do Séc. XIX. Nos primórdios do Séc. XX a homossexualidade foi incluída no ramo das doenças mentais e foram criadas clínicas para tratar os "doentes homossexuais" (Herek, 2004). A junção da visão médica às ideias emergentes da pureza racial e eugenia nos anos 1930s tiveram consequências desastrosas: cerca de 20.000 homossexuais masculinos, identificados por um triângulo cor-de-rosa, foram mortos em campos de concentração pelos Nazis (Naphy, 2004).

Apesar do movimento de liberação dos homossexuais ter começado a dar os seus sinais desde o início do Séc. XIX deve-se esperar os anos 1960s para observar uma progressiva tolerância para as minorias LGBT $^{3}$. Os movimentos de luta pelos direitos cívicos e igualdade social, económica e legal, da minoria negra e das mulheres nos EUA, e os acontecimentos do Maio de 68 francês promoveram, com efeito, ideias ligadas às liberdades civis democráticas, aos direitos das minorias, à igualdade entre homens e mulheres, brancos e negros, heterossexuais e homossexuais (Almeida, 2010).

É nesta altura, em 1972, que o psicólogo americano George Weinberg veio dar nome ao sentimento de hostilidade para com as pessoas homossexuais, designando por "homofobia" o medo irracional face à homossexualidade ou às pessoas homossexuais (Herek, 2004). A passagem da visão patologizante dos/as homossexuais para o enquadramento da intolerância dos/as heterossexuais chamou a atenção para a rejeição, hostilidade ou desprezo que as pessoas homossexuais sentiam por parte da sociedade. A homofobia, juntamente com outras formas de discriminação e intolerância, começou a formar um objecto de interesse e de estudo (Herek, 2004). Um ano após o aparecimento do termo homofobia a homossexualidade deixou de ser considerada, nos EUA, uma doença mental, sendo retirada do DSM (Diagnostic and Statistical Manual of Mental Disorders) (Rede ex aequo, 2006).

${ }^{3}$ Lésbica, gay, bissexual e transgénero. 
Por esta altura, a Revolução de 25 de Abril de 1974 trouxe consigo a restauração da liberdade de associação e de expressão, sendo por isto um grande marco no movimento LGBT em Portugal. Em 1982 a homossexualidade foi descriminalizada e os princípios da igualdade de direitos e de oportunidades encontraram-se fortalecidos com a adesão de Portugal à União Europeia em 1986 (Santos, 2005).

Desde o ano 2000, os avanços mais significativos da luta do movimento LGBT internacional focam-se em diversos momentos-chave. Em Dezembro de 2000 é aprovada a Carta dos Direitos Fundamentais da União Europeia que decreta: "Qualquer discriminação com base em qualquer natureza como sexo, raça, cor, etnia ou origem social, característica genética, (...) ou orientação sexual deve ser proibida". Em 2001, a Holanda é o primeiro país que permite o casamento civil entre pessoas do mesmo sexo e um ano depois a Suécia passa a permitir a adopção por casais homossexuais.

A alteração mais recente no panorama jurídico português no que diz respeito às políticas da sexualidade é a lei $\mathrm{n}^{\circ} 9 / 2010$ de 31 de Maio, que permite o casamento civil entre pessoas do mesmo sexo. Curiosamente, esta lei foi promulgada no dia 17 de Maio de 2010, o Dia Internacional da Luta contra a Homofobia. Todavia, estas conquistas não foram acompanhadas pelo desaparecimento da homofobia.

\section{A homofobia e os seus efeitos}

A homofobia pode revelar-se sob várias formas. Por exemplo, o heterossexismo é a manifestação da homofobia nas instituições sociais que, através dos seus discursos e retóricas sobre o género, a tradição ou a moralidade, tentam manter os estatutos tanto do grupo dominante como do grupo desviante, denegrindo qualquer comportamento ou relação não heterossexual (Herek, 2004). O preconceito sexual é um "pré-julgamento", uma resposta afectiva ou emocional, geralmente negativa, ao grupo de pessoas não heterossexuais ou a um membro deste grupo (Schneider, 2004).

Embora na actualidade as normas sociais das sociedades ocidentais tornarem pouco aceitável a manifestação explícita de atitudes preconceituosas, a expressão aberta do preconceito é socialmente melhor aceite quando este é dirigido à minoria homossexual do que a outros grupos (Schneider, 2004). Por conseguinte, as atitudes negativas para com as pessoas que violam as normas de género ainda se traduzem, por vezes, em manifestações de hostilidade exacerbada e de violência verbal e física (LaMar \& Kite, 1998). Por exemplo, um inquérito realizado recentemente nos EUA através da Internet revela que 50\% dos respondentes homossexuais de ambos os sexos foram vítimas de assédio verbal, que $37.6 \%$ de homens e $12.5 \%$ de mulheres 
homossexuais foram vítimas de agressões ou de crimes cometidos contra a propriedade, e que mais de $10 \%$ sofreram discriminações na procura de emprego ou de alojamento (Herek, 2009).

Apesar de se observar, na Europa e nos dois sub-continentes americanos, que as pessoas mais jovens aceitam geralmente melhor a homossexualidade (Pew Research Center, 2007), constata-se um aumento da radicalização da homofobia junto de certos jovens. Um relatório da associação SOS-Homophobie revela, por exemplo, que em 11 dos 14 homicídios homofóbicos cometidos em França entre 2002 e 2008, os agressores tinham menos de 26 anos e que, em cinco destes, jovens menores eram implicados ${ }^{4}$ (AFP, 2008).

A homofobia continua também a manifestar-se nas profissões da saúde (Brotman, Jalbert, Rowe \& Ryan, 2002): Estudos revelam que 89\% das pessoas ligadas aos serviços de saúde manifestam reacções negativas (como embaraço, rejeição, ou excessiva curiosidade) quando um/uma paciente se identifica como sendo gay ou lésbica. Existem diversas situações onde a homofobia se manifesta, como no facto do/a companheiro/a não ter direito às visitas em caso de internamento do/a outro/a nos cuidados intensivos, não o/a poder acompanhar na ambulância, e não ter direito a conhecer o seu estado de saúde.

De forma mais geral, o preconceito sexual manifesta-se na população heterossexual de duas formas (Morrison \& Morrison, 2002): O preconceito "clássico", explícito, tem por base objecções tradicionais e morais que desaprovam a homossexualidade (e.g. a homossexualidade é uma perversão, o comportamento homossexual é errado, os homossexuais são nojentos). O preconceito "moderno", implícito, manifesta-se de forma mais subtil na oposição à extensão dos direitos civis das pessoas heterossexuais às pessoas homossexuais ou na crença de que a minoria homossexual está a perseguir vantagens ou direitos imerecidos (e.g. muitos/as homossexuais usam a sua orientação sexual para obter privilégios especiais; os/as homossexuais tornaram-se demasiado exigentes na sua luta por direitos iguais). Os dois tipos de preconceito podem ser medidos, respectivamente, através da escala ATLG (Attitudes Toward Lesbians and Gay Men, Herek, 1988) e da escala MHS (Modern Homonegativity Scale, Morrison \& Morrison, 2002). A investigação revela que os níveis de preconceito implícito das pessoas heterossexuais são mais elevados do que os seus níveis de preconceito explícito (Morrison $\&$ Morrison, 2002), apesar dos dois tipos de preconceito estarem correlacionados (Morrison, Kenny \& Harrington, 2005).

\footnotetext{
${ }^{4}$ Pode-se recordar também o caso de Gisberta, um transsexual que foi morto em 2006 no Porto por 14 rapazes, todos, excepto um, com idade inferior a 16 anos.
} 
Existem, como é óbvio, diferenças inter-individuais nos níveis de preconceito sexual que provêm de diversos factores (ver Poeschl, 2011). Por exemplo, muitos estudos revelam que as mulheres são, em média, mais tolerantes para com a homossexualidade do que os homens e que, na actualidade como no passado, a homossexualidade feminina é melhor aceite do que a homossexualidade masculina (Ellis, Kitzinger \& Wilkinson, 2002). Existem, ainda, diferenças na expressão do preconceito que provêm das motivações das pessoas para responder de forma (não) preconceituosa (Plant \& Devine, 1998): Algumas pessoas são motivadas a não se mostrar preconceituosas por causa das suas atitudes, crenças e valores pessoais; outras por conformidade às normas actuais de igualdade, independentemente das suas crenças pessoais; outras, ainda, não se preocupam com as normas sociais e não se importam de exprimir abertamente os seus preconceitos. Plant e Devine (1998) verificaram que as motivações internas, mas não as externas, estão correlacionadas com medidas auto-relatadas de atitudes preconceituosas: quanto mais baixo o nível de preconceito, mais forte a motivação interna para controlar o preconceito (Bernardes, 2003).

Juntamente com os silêncios, ausências e evasões que as rodeiam (Carneiro \& Menezes, 2004), o heterossexismo e o preconceito sexual são barreiras que impedem as pessoas homossexuais de se sentir confortáveis com a sua orientação sexual e de a revelar sem problemas. De facto, muitos gays e lésbicas optam por não se assumirem publicamente mesmo se, para os psicólogos e profissionais da saúde, os benefícios da revelação da homossexualidade são maiores do que os seus custos. Segundo os especialistas, os benefícios da revelação da homossexualidade são o bem-estar psicológico, o aumento da auto-estima e a redução do stress mental, a diminuição dos comportamentos de risco e a facilitação das relações interpessoais, enquanto que os seus custos podem incluir as represálias físicas, o evitamento e a reprovação social (Corrigan \& Matthews, 2003).

Num recente estudo (Costa, 2008) realizado em Portugal com o objectivo de conhecer a opinião das pessoas heterossexuais sobre as consequências da revelação ou não revelação da homossexualidade, verificou-se que a opinião dos especialistas era partilhada pelas pessoas leigas: Apesar de considerarem que as consequências da homossexualidade são negativas seja qual for a decisão tomada, as pessoas inquiridas pensam que as consequências da revelação da homossexualidade são menos negativas do que as da não revelação (Costa \& Poeschl, 2010). Mais precisamente, elas acreditam que a revelação da orientação sexual permite às pessoas homossexuais ter uma melhor imagem de si ou uma vida social mais preenchida por intermédio de relacionamentos mais saudáveis, mesmo se os riscos de retaliação são maiores como consequência da revelação da orientação sexual, por oposição à não revelação. 
Constatou-se, ainda, neste estudo, que as representações da homossexualidade se organizam, sobretudo, à volta da figura dos homossexuais masculinos, descritos de forma depreciativa. Observou-se também uma menor aceitação dos homens gays do que das mulheres lésbicas: os gays despertam menos sentimentos positivos e atitudes mais preconceituosas do que as lésbicas, e as consequências da revelação da homossexualidade são vistas como menos positivas para os gays do que para as lésbicas (Costa, 2008).

$\mathrm{Na}$ sequência destes resultados considerámos relevante examinar a representação que a minoria homossexual tem acerca da maneira de pensar da maioria heterossexual e a relação entre esta representação e a decisão de revelar, ou não, a orientação sexual. Não há dúvida de que as pessoas homossexuais têm uma representação da forma como a maioria heterossexual se posiciona face à sua categoria, e que esta representação se constrói e se desenvolve no decurso das interacções sociais. Assim, a representação integra, para além das experiências próprias, observações, testemunhos, opiniões e juízos provenientes de múltiplas fontes, tratando-se, portanto, de uma representação social (Moscovici, 1976; ver também Poeschl, 2003). Foi amplamente demonstrado que as representações sociais orientam o comportamento (ver, por exemplo, Jodelet, 1989) e, por isso, podemos supor que a representação da forma como a maioria heterossexual pensa acerca das pessoas homossexuais influencia a decisão destas últimas de revelar ou não a sua orientação sexual.

\section{Objectivos e hipóteses}

O nosso estudo tem como objectivo examinar em que medida as consequências percepcionadas da revelação, ou não revelação, da orientação sexual estão relacionadas com os níveis de preconceito (explícito e implícito), e com os níveis de motivação (interna e externa) para responder de forma não preconceituosa atribuídos à população heterossexual por parte de respondentes homossexuais (ver também Venâncio, 2010). Na medida em que a homossexualidade feminina é geralmente melhor aceite do que a homossexualidade masculina, o estudo centrou-se sobre a situação dos homens gays. Formularam-se três grupos de hipóteses.

Segundo a literatura, os especialistas (por exemplo Corrigan \& Matthews, 2003) consideram que a revelação da homossexualidade aumenta, por um lado, o bem-estar psicológico e a auto-estima e, por outro, o risco de isolamento social e de represálias físicas, uma opinião partilhada pelas pessoas leigas inquiridas por Costa (Costa \& Poeschl, 2010). Em linha com estes resultados, prevemos que os/as homossexuais considerem que os homens homossexuais não assumidos têm uma maior probabilidade de expe- 
rimentar sentimentos negativos (medo, frustração, vergonha, por exemplo) do que os homossexuais assumidos (Hipótese 1a) e que os homossexuais assumidos têm uma maior probabilidade de serem discriminados do que os homossexuais não assumidos (Hipótese 1b).

Para vários autores, o preconceito para com as pessoas homossexuais pode manifestar-se sob uma forma explícita ou implícita (Morrison \& Morrison, 2002), e muitos estudos revelam que o preconceito explícito tem valores inferiores ao preconceito implícito (Morrison \& Morrison, 2002; Costa, 2008). Sendo assim, esperamos que os/as homossexuais irão considerar que o nível de preconceito implícito da população heterossexual é superior ao seu nível de preconceito explícito (Hipótese 2a). Esperamos, ainda, que a percepção de níveis mais elevados de preconceito, quer explícito, quer implícito, esteja associada com a percepção de consequências mais negativas, quer da revelação quer da não revelação da homossexualidade (Hipótese $2 b)$.

Diversos estudos demonstraram que o preconceito da população heterossexual em relação às pessoas homossexuais pode não se exprimir abertamente por motivação interna (reflectindo uma atitude estruturada a partir de princípios e experiências pessoais) ou por motivação externa (reflectindo um carácter mais transitório da expressão do preconceito influenciado sobretudo pelo contexto e pelas normas sociais) (Plant \& Devine, 1998). A motivação interna (mas não a motivação externa) está inversamente correlacionada com o nível de preconceito que as pessoas heterossexuais admitem possuir (Plant \& Devine, 1998), parecendo estas últimas ter uma maior motivação interna do que externa para responderem de forma não preconceituosa perante a homossexualidade (Costa, 2008). De acordo com estes resultados, prevemos que os/as homossexuais considerem que a população heterossexual tem uma maior motivação interna do que externa para responder de forma não preconceituosa em relação aos homens homossexuais (Hipótese 3a); que os níveis de preconceito e os níveis de motivação interna para responder sem preconceito atribuídos à população heterossexual estarão negativamente correlacionados (Hipótese 3b), e que os níveis de motivação quer interna quer externa para responder de forma não preconceituosa estarão negativamente correlacionados com a probabilidade da revelação da homossexualidade acarretar consequências negativas (Hipótese 3c).

\section{Método}

\section{Respondentes}

Participaram neste estudo 90 respondentes, 47 homens e 43 mulheres, todos/as autoidentificados/as como sendo homossexuais ou bissexuais. São 
na sua maioria estudantes $(67.80 \%)$, e têm idades compreendidas entre os 14 e os 42 anos $(M=23$ anos $)$.

\section{Questionário}

Os dados foram recolhidos por meio de um questionário adaptado do instrumento utilizado por Costa (2008). O estudo era introduzido pelo seguinte texto: "A questão da homossexualidade está, actualmente, no centro de inúmeros debates, quer na comunicação social, quer nas conversas privadas. O presente questionário faz parte duma vasta investigação que incide sobre diversos aspectos das relações entre os grupos sexuais".

Seguiam-se três grupos de questões:

O primeiro grupo era composto pelos dez itens da Escala de Motivação Interna (IMS) e da Escala de Motivação Externa (EMS) para responder de forma não preconceituosa (Plant \& Devine, 1998), já traduzidas para o português e utilizadas por Costa (2008). Os itens tinham sido modificados no sentido de referir as motivações "das pessoas" em vez das motivações do respondente para não se mostrar preconceituoso em relação aos homossexuais. Os/as respondentes deviam indicar em que medida concordavam com cada uma das proposições ( $1=$ discordo totalmente; $7=$ concordo totalmente).

O segundo grupo de itens, sobre as consequências da revelação ou não revelação da homossexualidade, era precedido de uma citação retirada da revista mensal Com'Out que denunciava o preconceito e a discriminação enquanto barreiras à assumpção da orientação homossexual. Os/as respondentes deviam exprimir a sua opinião sobre a probabilidade $(1=$ totalmente improvável; 7 = totalmente provável) de uma pessoa homossexual assumida e uma pessoa homossexual não assumida experimentarem cada uma das dezanove consequências apresentadas. Os itens foram retirados do estudo de Costa (2008), tendo sido escolhidas as consequências referidas por sete ou mais participantes nesse estudo, e incluiu ainda o sentimento de "insegurança" que, pela recolha de testemunhos junto do meio LGBT, se julgou importante acrescentar.

O terceiro grupo, sobre as atitudes para com os homossexuais, era formado pelos dez itens da escala ATG (Attitudes Toward Gay Men, Herek, 1988) e os dez itens da escala MHS (Modern Homonegativity Scale, Morrison \& Morrison, 2002), também traduzidas para o português e utilizadas por Costa (2008). Os/as respondentes deviam indicar as respostas que, segundo eles/as, a maioria das pessoas dariam às vinte afirmações $(1=$ discordo totalmente; 7 = concordo totalmente).

O último grupo de itens era destinado a recolher os dados sócio-demográficos e no fim do questionário eram ainda incluídas algumas linhas para recolher a opinião dos/as respondentes sobre o questionário. 


\section{Procedimento}

A recolha de dados foi efectuada através da técnica de Snowball (Goodman, 1960), através das redes sociais e através do contacto com associações que promovem reuniões e encontros entre LGBT's, nomeadamente a Rede ex aequo, facilitando assim o encontro com esta comunidade.

\section{Análise dos dados}

De acordo com a literatura, foram criadas duas escalas de motivação para responder de forma não preconceituosa: uma escala de motivação externa, com um valor de $\alpha$ de Cronbach de .80, e uma escala de motivação interna, reduzida a três itens de modo a obter uma consistência interna satisfatória ("As pessoas estão pessoalmente motivadas para agir de uma forma não-preconceituosa em relação aos homossexuais", "As pessoas tentam agir de uma forma não preconceituosa em relação aos homossexuais porque é importante para elas", "Devido aos seus valores pessoais, as pessoas acreditam que o uso de estereótipos em relação aos homossexuais é errado") com um valor de $\alpha$ de Cronbach de .645. Foram também criadas duas escalas de atitudes preconceituosas para com os homossexuais: uma escala de atitudes explícitas, com um valor de $\alpha$ de Cronbach de .94, e uma escala de atitudes implícitas, com um valor de $\alpha$ de Cronbach de .92.

Aplicou-se uma análise factorial em componentes principais sobre os 19 itens que foram por nós seleccionados para conferir a existência de dois tipos de consequências que podem advir da revelação ou não revelação da orientação sexual.

As análises de variância aplicadas sobre as diferentes escalas não revelaram nenhum efeito principal ou de interacção envolvendo o sexo de pertença dos respondentes. Por isso, não referimos esta variável na apresentação dos resultados.

\section{Resultados e discussão}

Consequências da decisão de revelar ou de não revelar a homossexualidade

A análise factorial em componentes principais aplicada sobre o conjunto das 19 consequências que podem advir de revelar e de não revelar a

\footnotetext{
${ }^{5}$ Com todos os itens, o valor de $\alpha$ de Cronbach era de .45. Comparativamente, no estudo realizado com respondentes heterossexuais por Costa (2008), os valores de $\alpha$ de Cronbach foram de .76 para a motivação interna e .81 para a motivação externa.
} 
homossexualidade extraiu dois factores com valores próprios superiores a um. Eles explicam, no conjunto, $62.07 \%$ da variância total e referem, respectivamente, os sentimentos negativos e a discriminação. O Quadro 1 apresenta a solução factorial após rotação varimax.

Quadro 1: Consequências da (não) revelação da orientação sexual. Solução factorial após rotação varimax.

Factor 1

Factor 2

\begin{tabular}{lcc}
\hline \hline Sentimentos negativos (42.55\%) & .86 & -.01 \\
Depressão & .86 & -.07 \\
Angústia & .83 & -.05 \\
Baixa auto-estima & .81 & .06 \\
Isolamento & .80 & -.20 \\
Frustração & .78 & .01 \\
Culpa & .78 & -.00 \\
Solidão & .78 & .05 \\
Insegurança & .77 & -.33 \\
Sentimento de mentir & .74 & -.05 \\
Infelicidade & .71 & .10 \\
Medo & .68 & .02 \\
Vergonha & .68 & .13 \\
Revolta & & \\
Discriminação (19.53\%) & & \\
Exclusão & -.15 & .84 \\
Dificuldades profissionais & -.04 & .83 \\
Dificuldades sociais & -.05 & .83 \\
Desprezo & .26 & .72 \\
Discriminação & -.34 & .70 \\
Preconceito & .19 & .67 \\
\hline
\end{tabular}


Construímos duas escalas reunindo os itens agrupados pelos factores, uma de sentimentos negativos e outra de discriminação, tendo os valores do $\alpha$ de Cronbach revelado uma consistência interna satisfatória (sentimentos negativos: $\alpha=.95$; discriminação: $\alpha=.86$ ). As médias que indicam a probabilidade dos sentimentos negativos e da discriminação serem consequências da revelação ou não revelação da homossexualidade estão registadas no Quadro 2. Estes valores sugerem que os/as respondentes julgam ser pouco provável que os homossexuais assumidos experimentem sentimentos negativos e que os homossexuais não assumidos sejam discriminados. Sugerem, ainda, que os respondentes julgam, pelo contrário, existir uma forte probabilidade que os homossexuais assumidos sejam discriminados e que os homossexuais não assumidos experimentem sentimentos negativos.

Quadro 2: Consequências da revelação e da não revelação da homossexualidade (1 = totalmente improvável; 7 = totalmente provável).

\begin{tabular}{lcc}
\hline & Sentimentos negativos & Discriminação \\
\hline \hline Revelação & 3.50 & 5.02 \\
Não revelação & 5.51 & 3.70 \\
\hline
\end{tabular}

A análise de variância que cruza os dois tipos de consequências com a decisão de revelar ou não revelar a homossexualidade indica um efeito significativo das consequências, $F(1,89)=7.24, p=.009$, um efeito significativo da decisão, $F(1,89)=6.53, p=.012$, assim como uma interacção significativa entre as consequências e a decisão, $F(1,89)=176.03, p<.001$. O efeito das consequências sugere que os sentimentos negativos têm uma maior probabilidade de ser uma consequência da homossexualidade (assumida ou não assumida) do que a discriminação (sentimentos negativos: 4.50; discriminação: 4.36$), t(89)=2.69, p=.009$. O efeito da decisão indica que os homossexuais assumidos têm uma menor probabilidade de experimentar consequências negativas do que os homossexuais não assumidos (assumidos: 4.26; não assumidos: 4.60$), t(89)=2.56, p=.012$. Finalmente, a interacção significativa entre consequências e decisão mostra que os/as respondentes consideram, em conformidade com a nossa Hipótese 1a, que os homossexuais não assumidos têm uma maior probabilidade de experimentar sentimentos negativos do que os homossexuais assumidos, $t(90)=13.34, p<.001$, e que, em conformidade com a nossa Hipótese $1 \mathrm{~b}$, os homossexuais assumidos têm uma maior probabilidade de ser discriminados do que os homossexuais não assumidos, $t(90)=6.28, p<.001$. 
Para saber se os/as respondentes consideram que a probabilidade de os homossexuais assumidos terem sentimentos negativos e serem alvo de discriminação é inversa à probabilidade de os homossexuais não assumidos experimentarem as mesmas consequências, examinámos a relação entre as respostas fornecidas nas duas situações (ver Quadro 3). Constatámos que a correlação entre a probabilidade de ver os homossexuais assumidos e os homossexuais não assumidos experimentar sentimentos negativos é nula, $r=$ $.02, n s$, mas que existe uma correlação negativa significativa entre a probabilidade de ver os homossexuais assumidos e os homossexuais não assumidos ser alvos de discriminação, $r=-.22, p=.036$ : quanto mais os/as respondentes consideram que os homossexuais assumidos são discriminados, menos consideram que os homossexuais não assumidos também o são. A decisão de revelar ou não a homossexualidade aparece portanto ligada às expectativas de ser ou não alvo de discriminação.

Procurámos então saber se a maior probabilidade de sofrer discriminação que resulta da revelação da homossexualidade era vista como compensada por uma menor probabilidade de experimentar sentimentos negativos, e se a maior probabilidade de experimentar sentimentos negativos que resulta da não revelação da homossexualidade era vista como compensada por uma menor probabilidade de ser discriminado. Observou-se (Quadro 3) que os sentimentos negativos e a discriminação estão positivamente correlacionados, quer quando se consideram homossexuais não assumidos, $r=.27$, $p=.011$, quer (e ainda mais) quando se consideram homossexuais assumidos, $r=.50, p<.001$. Por outras palavras, as duas consequências prováveis da homossexualidade não são vistas como sendo compensadas uma pela outra, mas sim como sendo reciprocamente reforçadas: quanto mais os/as respondentes consideram provável que os homossexuais experimentem sentimentos negativos devidos à sua homossexualidade, mais eles consideram também que é provável que os homossexuais sejam alvo de discriminação.

Pode finalmente notar-se no Quadro 3 que todas as correlações entre discriminação e sentimentos negativos são positivas e significativas: a percepção de que os homossexuais não assumidos experimentam sentimentos negativos está associada com a percepção de uma forte probabilidade de que os homossexuais assumidos sejam discriminados, $r=.42, p<.001$; por outro lado, a percepção de que os homossexuais assumidos são discriminados está relacionada com a percepção de que os homossexuais não assumidos experimentam sentimentos negativos, $r=.22, p=.038$. Este resultado parece, portanto, traduzir a existência de diferenças na amplitude do sentimento de transtorno associado à homossexualidade. 
Quadro 3: Correlação $r$ de Pearson entre os sentimentos negativos e a discriminação experimentados pelos homossexuais, em função da revelação ou não revelação da orientação sexual $(\mathrm{N}=90)$.

$$
\text { Revelação Não revelação }
$$

Sentimentos Discriminação Sentimentos Discriminação

\begin{tabular}{|c|c|c|c|c|c|}
\hline & Sentimentos & --- & & & \\
\hline \multicolumn{6}{|c|}{ Revelacão } \\
\hline & Discriminação & $+.50 * * *$ & --- & & \\
\hline Não & Sentimentos & +.02 & $+.42 * * *$ & --- & \\
\hline revelação & Discriminação & $+.22 *$ & $-.22 *$ & $+.27 *$ & --- \\
\hline
\end{tabular}

\section{Percepção do nível de preconceito}

Os níveis de preconceito atribuídos pelos/as respondentes à população heterossexual não são muito elevados: 2.96 para a escala ATG de preconceito explícito e 3.59 para a escala MHS de preconceito implícito (numa escala de 1 a 7 onde 7 indica a percepção de um elevado nível de preconceito). De facto, estes valores são significativamente inferiores ao ponto médio das duas escalas, ATG: $t(89)=5.70, p<.001$; MHS: $t(89)=2.63, p=.010$.

Como verificado na literatura, os níveis de preconceito medidos pelas duas escalas são correlacionados, $r=.80, p<.001$ : quanto mais elevados são os níveis de preconceito explícito atribuídos à população heterossexual, tanto mais elevados são também os níveis de preconceito implícito percepcionados. Por sua vez, uma comparação entre os níveis médios das duas escalas indica que os/as respondentes consideram, tal como predito pela nossa Hipótese $2 \mathrm{a}$, que o nível de preconceito implícito da população heterossexual é superior ao seu nível de preconceito explícito, $t(89)=5.65, p<.001$.

O fraco nível de preconceito atribuído pelos/as respondentes homossexuais à população heterossexual contrasta com a percepção das consequências da homossexualidade. Contudo, ao examinar em que medida os níveis de preconceito atribuídos à população heterossexual estavam correlacionados com as consequências percepcionadas da (não) revelação da homossexualidade, verificou-se, curiosamente, que as correlações calculadas não atingiam o nível de significância (todos os $p s>.10$ ). Portanto, contrariamente à predição da nossa Hipótese $2 b$, a percepção de níveis mais elevados de preconceito, quer explíci- 
to, quer implícito, não está associada com a percepção de consequências mais negativas, quer da revelação quer da não revelação da homossexualidade. O facto das consequências percepcionadas da (não) revelação da homossexualidade serem independentes do nível de preconceito atribuído à população em geral sugere que, para os homossexuais, o problema colocado pela homossexualidade é mais relacionado com o comportamento de alguns e menos com a maneira de pensar da população em geral.

\section{Percepção da motivação para responder de forma não preconceituosa}

A motivação percepcionada para responder de forma não preconceituosa em relação aos homossexuais não é muito elevada (motivação externa: 3.71; motivação interna: 3.07, numa escala de 1 a 7 onde 7 indica a percepção de um elevado nível de motivação). Estes valores também são significativamente inferiores à média das escalas (motivação externa: $t(89)=2.46, p$ $=.016$; motivação interna: $t(89)=8.54, p<.001$ ). Por conseguinte, se os/as respondentes homossexuais percepcionam a população heterossexual como não muito preconceituosa, eles/as também consideram que ela não tem uma forte motivação para responder de forma não preconceituosa.

Uma comparação entre os níveis de motivação interna e os níveis de motivação externa atribuídos pelos/as homossexuais à população heterossexual para responder sem preconceito revela que, de forma geral, a motivação externa para responder de forma não preconceituosa em relação aos homossexuais é percepcionada como significativamente maior do que a motivação interna, $F(1,88)=23.45, p<.001$, o que é contrário ao que previa a nossa Hipótese 3a.

Infirmando também o que previa a nossa Hipótese 3b, os níveis de preconceito e os níveis de motivação interna para responder de forma não preconceituosa atribuídos pelos/as homossexuais à população heterossexual não estão negativamente mas positivamente correlacionados: ATG: $r=.22$, $p=.041$; MHS: $r=.28, p=.007$. Apesar da motivação externa para responder de forma não preconceituosa em relação aos homossexuais não estar correlacionada com os dois tipos de preconceitos (ATG: $r=.09, n s$; MHS: $r$ $=.18, n s$ ), a motivação interna e a motivação externa são correlacionadas entre si, $r=.35, p=.001$.

Parece portanto que quanto mais os/as respondentes homossexuais percepcionam as pessoas heterossexuais como preconceituosas, tanto mais eles/as acham que estas pessoas devem apelar aos seus valores pessoais para não deixar transparecer o preconceito sexual. Pelo contrário, as pressões sociais externas são vistas como algo que exerce efeitos diversificados sobre o comportamento da população heterossexual, incluindo o de poderem reforçar a motivação interna dos/as heterossexuais para responder de forma não preconceituosa. 
Uma análise das correlações entre a motivação externa e a motivação interna para responder de forma não preconceituosa com as expectativas de experimentar sentimentos negativos e sofrer de discriminação não revelou relações significativas em caso de não revelação da orientação sexual. Contudo, evidenciou duas relações significativas em caso de revelação da homossexualidade: a motivação externa encontra-se positivamente correlacionada com os sentimentos negativos dos homossexuais, $r=.21, p=.046$, e a motivação interna associada, negativamente, com a probabilidade de ser alvo de discriminação, $r=-.26, p=.015$.

Estas correlações sugerem que quanto mais os/as respondentes homossexuais atribuem os comportamentos não preconceituosos às pressões sociais, mais eles/as pensam que os homossexuais assumidos experimentam sentimentos negativos. Por outro lado, quanto mais eles/as atribuem os comportamentos não preconceituosos a considerações pessoais, menos eles/as pensam que os homossexuais assumidos possam ser alvos de discriminação. Estes resultados apoiam parcialmente a nossa Hipótese $3 \mathrm{c}$ que previa que os dois tipos de motivação para responder sem preconceito estariam negativamente correlacionados com a probabilidade da revelação da homossexualidade acarretar consequências negativas.

Os fracos níveis de motivação externa e de motivação interna percepcionados pelos/as respondentes homossexuais poderiam explicar a percepção, respectivamente, de uma fraca probabilidade dos homossexuais assumidos experimentarem sentimentos negativos e de uma forte probabilidade deles serem discriminados. Mais importante contudo, as relações evidenciadas entre os níveis de motivação percepcionados e as consequências da revelação da homossexualidade sugerem que a decisão de revelar a orientação sexual depende mais das motivações para responder sem preconceito do que dos níveis de preconceito atribuídos à população heterossexual. Procurámos portanto perceber melhor as razões da não verificação das nossas hipóteses relativas aos tipos de motivação e aos níveis de preconceito, comparando os nossos resultados com os resultados obtidos por Costa (2008).

\section{Niveis de preconceito e de motivação declarados e atribuídos}

Os níveis de preconceito e de motivação declarados pelos/as respondentes heterossexuais e atribuídos a estes/as pelos/as respondentes homossexuais, registados no Quadro 4, mostram que apenas o nível de preconceito explícito declarado pelos/as heterossexuais não é significativamente diferente do nível de preconceito que lhes é atribuído pelos/as homossexuais (homossexuais: 2.96; heterossexuais: 3.26), $t(167)=1.25, n s$. Pelo contrário, e curiosamente, o nível de preconceito implícito declarado pelos/as heterossexuais é significativamente superior ao nível que os/as respondentes homossexuais sentem existir nesta população (homossexuais: 3.59; heteros- 
sexuais: 4.15), $t(167)=2.73, p=.007$. Este facto, surpreendente quando se consideram as consequências negativas atribuídas à homossexualidade pelos/as homossexuais, corrobora a ideia já expressa de que o problema colocado pela homossexualidade não está muito relacionado com a maneira de pensar atribuída à população em geral. Estas consequências poderiam ser sobretudo, como já sugerido também, relacionadas com o comportamento de alguns ou, alternativamente, com aspectos que não são apreendidos pelos itens das escalas de preconceito explícito ou de preconceito implícito, dado que ambas recolhem um fraco acordo.

Quadro 4: Níveis de preconceito e de motivação declarados pelos heterossexuais e atribuídos a esta população pelos homossexuais.

\begin{tabular}{lccc}
\hline & $\begin{array}{c}\text { Homossexuais } \\
(\mathrm{n}=90)\end{array}$ & $\begin{array}{c}\text { Heterossexuais } \\
(\mathrm{n}=79)\end{array}$ & $t(167)$ \\
\hline ATG & 2.96 & 3.26 & 1.25 \\
\hline MHS & 3.59 & 4.15 & $2.73^{* *}$ \\
\hline Motivação externa & 3.71 & 2.56 & $5.68^{* * *}$ \\
\hline Motivação interna & 3.07 & 5.22 & $11.86^{* * *}$ \\
\hline
\end{tabular}

$* * *: \mathrm{p} \leq .001 ; * * \mathrm{p} \leq .01$

Pode-se também constatar, do Quadro 4, que os níveis de motivação externa para responder de forma não preconceituosa declarados pelos/as heterossexuais são inferiores aos que são atribuídos a esta população pelos/as homossexuais (homossexuais: 3.71 ; heterossexuais: 2.56 ), $t(167)=$ $5.68, p<.001$, enquanto que os níveis de motivação interna declarados pelos/as heterossexuais são muito superiores aos que os/as homossexuais sentem existir (homossexuais: 3.07; heterossexuais: 5.22), $t(167)=11.86, p$ $<.001$.

As diferenças constatadas entre as respostas dos/as heterossexuais e dos/as homossexuais podem sugerir várias interpretações. Por um lado, pode-se considerar que os elevados níveis de motivação interna e os baixos níveis de motivação externa declarados pelos/as heterossexuais resultam de um efeito de desejabilidade social (cf. Krosnick, 1999). Alternativamente, a discrepância entre os níveis declarados pelos/as heterossexuais e os níveis atribuídos a estes/as pelos/as homossexuais poderia provir de uma tendência, por parte dos/as heterossexuais, para atribuir a factores internos, disposicionais, a causa dos seus comportamentos positivos, e/ou de uma tendência, por 
parte dos/as homossexuais, para atribuir os comportamentos positivos da maioria heterossexual a factores externos, situacionais (ver, a este respeito, Hewstone, 1989). Por último, a diferença entre as percepções dos/as homossexuais e as declarações dos/as heterossexuais poderia também surgir de uma falta de contacto entre as duas comunidades. A este respeito, é importante sublinhar que uma maior interacção entre heterossexuais e homossexuais é geralmente considerada como sendo um dos factores mais eficazes para diminuir a prevalência do preconceito sexual (LaMar \& Kite, 1998; Costa, 2008).

\section{Conclusão}

A questão da homossexualidade é uma temática que tem vindo a ganhar cada vez maior visibilidade. Por um lado parece começar a existir uma maior tolerância por parte da população heterossexual para com os direitos da minoria homossexual, por outro, mais pessoas homossexuais começam a arriscar-se a revelar a sua orientação sexual. Surgem igualmente cada vez mais estudos sobre esta temática. No entanto a sua grande maioria é conduzida junto da população heterossexual. O nosso estudo procurou dar voz à população homossexual a fim de conhecer a sua visão do "mundo exterior".

Os nossos resultados revelam que os homossexuais são confrontados com um difícil dilema quando devem escolher entre revelar ou não revelar a sua orientação sexual. Em conformidade com a opinião dos especialistas e das pessoas leigas, os/as respondentes homossexuais consideram que os homossexuais não assumidos têm uma maior probabilidade de experimentar sentimentos negativos mas podem esperar ser menos discriminados do que os homossexuais assumidos.

Contradizendo as nossas expectativas, as consequências previstas da (não) revelação da homossexualidade não estão relacionadas com os níveis de preconceito atribuídos à população em geral. A percepção de níveis de preconceito mais elevados na população heterossexual é contudo associada à percepção de uma maior motivação interna para responder de forma não preconceituosa, como se, na representação dos/as homossexuais, era a consciência do preconceito que activava os mecanismos internos susceptíveis de reduzir a sua expressão. Esta explicação poderia encontrar algum apoio nos resultados do estudo de Costa (2008) onde foi observado que as pessoas heterossexuais inquiridas se consideravam pouco preconceituosas apesar das palavras depreciativas que associaram à homossexualidade (e.g.: "paneleiro", "bicha", ...).

Sendo a percepção de uma maior motivação interna também associada à percepção de uma menor probabilidade de discriminação em caso de reve- 
lação da homossexualidade, ela parece desempenhar um papel fundamental na decisão de revelar ou não a homossexualidade. Ora, as declarações dos/as heterossexuais acerca dos seus elevados níveis de motivação interna para responder sem preconceito não parecem ter eco nos meios homossexuais. Pelo contrário, a atribuição, à população heterossexual, de baixos níveis de motivação interna para se mostrar não preconceituosa deixa antever uma forte discriminação, o que poderá favorecer a não revelação da orientação sexual.

Ao identificar a representação que os/as homossexuais têm da maneira de pensar da população heterossexual acerca dos homens homossexuais, percebe-se que ainda há um grande caminho a percorrer para que os homossexuais possam se sentir confortáveis com a sua orientação sexual, o que levanta a questão do que poderá ser feito para facilitar esse processo. Protestar, educar e contactar, seriam as palavras-chave para este combate (Corrigan $\&$ Matthews, 2003). Protestar significa denunciar publicamente os casos de homofobia, e educar implica desmistificar os mitos que rodeiam a homossexualidade 6 .

Por fim, o contacto indispensável entre homossexuais e heterossexuais depende em grande parte da própria comunidade LGBT. Segundo Harvey Milk, o primeiro homem abertamente gay a ser eleito a um cargo público na Califórnia, “(...) se todos os gays advogados, todos os arquitectos gays se assumissem, se levantassem e deixassem que o mundo os conhecesse, tal faria mais do que podem imaginar (...)" (Corrigan \& Matthews, 2003, p. 235).

Em suma, quanto mais o tema da homossexualidade for debatido, quanto mais a "sociedade heterossexual" e a "sociedade homossexual" interagirem e promoverem em conjunto o debate público, maior abertura haverá, o que, certamente, facilitará o coming out pacífico e necessário a todos aqueles que ainda não o fizeram.

\section{Referências}

AFP (2008). Discrimination. - 'La lutte contre l'homophobie piétine'. $<$ http://tf1.lci.fr/infos/france/societe/0,,3850857,00-lutte-contre-homophobie-pietine-.html>.

Almeida, S. J. (2010). Homossexuais no Estado Novo. Porto: Sextante Editora.

Bernardes, D. L. G. (2003). Dizer 'não' aos estereótipos sociais: As ironias do controlo mental. Análise Psicológica, 21(3), 307-321.

\footnotetext{
6 Ver, por exemplo, o Projecto Educação desenvolvido pela Associação Rede ex aequo, que visa a disseminação de informação sobre os temas da homossexualidade, bissexualidade e transgenderismo entre professores e alunos (www.rea.pt).
} 
Brotman, S., Jalbert, Y., Rowe, B., \& Ryan, B. (2002). The impact of coming out on health and health care access: The experiences of gay, lesbian, bisexual and two-spirit people. Journal of Health \& Social Policy, 15(1), 1-28.

Carneiro, N., \& Menezes, I. (2004). Paisagens, caminhos e pedras: Identidade homossexual e participação política. In A. F. Cascais (Ed.), Indisciplinar a teoria: Estudos gays, lésbicos e queer (pp. 117-141). Lisboa: Fenda.

Corrigan, P. W., \& Matthews, A. K. (2003). Stigma and disclosure: Implications for coming out of the closet. Journal of Mental Health, 12(3), 235-248.

Costa, D. (2008). As representações sociais da homossexualidade e o papel da assumpção da identidade sexual e do sexo de pertença nas atitudes para com os homossexuais. Faculdade de Psicologia e de Ciências da Educação, Universidade do Porto: Dissertação de mestrado.

Costa, D., \& Poeschl, G. (2010) Représentations des hétérosexuel-les sur les conséquences, pour les homosexuel-les, de révéler ou de taire leur orientation sexuelle. X Conférence Internationale sur les Représentations Sociales (Tunis, Tunísia).

Ellis, S. J., Kitzinger, C., \& Wilkinson, S. (2002). Attitudes toward lesbians and gay men and support for lesbian and gay human rights among psychology students. Journal of Homosexuality, 44, 121-138.

Goodman, L. (1961). Snowball sampling. The Annals of Mathematical Statistics, 32(1), 148-154.

Herek, G. M. (1988). Heterosexuals' attitudes toward lesbians and gay men: Correlates and gender differences. Journal of Sex Research, 25, 451-477.

Herek, G. M. (2004). Beyond "homophobia": Thinking about sexual prejudice and stigma in the twenty-first century. Sexuality Research and Social Policy, 1(2), 6-24.

Herek, G. M. (2009). Hate crimes and stigma-related experiences among sexual minority adults in the United States: Prevalence estimates from a national probability sample. Journal of Interpersonal Violence, 24, 54-74.

Hewstone, M. (1989). Causal attribution: From cognitive processes to collective beliefs. Cambridge, MA: Blackwell.

Jodelet, D. (1989). Folies et représentations sociales. Paris: Presses Universitaires de France.

Krosnick, J. A. (1999). Survey Research. Annual Review of Psychology, 50, 537-567 .

LaMar, L., \& Kite, M. (1998). Sex differences in attitudes toward gay men and lesbians: A multidimensional perspective. Journal of Sex Research, 35, 189-196.

Morrison, T. G., Kenny, P., \& Harrington, A. (2005). Modern prejudice toward gay men and lesbian women: Assessing the viability of a measure of modern homonegative attitudes within an Irish context. Genetic, Social, and General Psychology Monographs, 131(3), 219-250.

Morrison, M. A., \& Morrison, T. G. (2002). Development and validation of a scale measuring modern prejudice toward gay men and lesbian women. Journal of Homossexuality, 43(2), 15-37. 
Moscovici, S. (1976). La psychanalyse, son image et son public. Paris: Presses universitaires de France.

Naphy, W. (2004). Born to be gay: A history of homosexuality. Stroud: Tempus.

Pew Research Center (2007). 47-nation Pew global attitudes survey. <http://pewglobal.org/reports/pdf/258.pdf>.

Plant, E. A., \& Devine, P. G. (1998). Internal and external motivation to respond without prejudice. Journal of Personality and Social Psychology, 75, 811-832.

Poeschl, G. (2003). Teoría de las representaciones sociales. In J. F. Morales \& C. Huici (Eds.), Estudios de Psicología Social (pp. 439-466). Madrid: UNED.

Poeschl, G. (2011). Homophobie, sexisme et justification de l'ordre social établi. In C. Fraïssé (Ed.), L’homophobie et les expressions de l'ordre hétérosexiste (pp. 67-84). Rennes: Presses Universitaires de Rennes.

Rede ex aеquo (2006). Manual de Coordenadores de Grupos de Jovens LGBT $\left(2^{a}\right.$ ed.).

Santos, A. C. (2005). Heteroqueers contra a heteronormatividade: Notas para uma teoria queer inclusiva. Oficina do CES, 239. < www.ces.uc.pt >.

Schneider, D. J. (2004). The psychology of stereotyping. Nova Iorque: The Guilford Press.

Venâncio, J. (2010). Homofobia e consequências da (não) assumpção da homossexualidade: Um estudo sobre a visão LGBT. Faculdade de Psicologia e de Ciências da Educação, Universidade do Porto: Dissertação de mestrado. 